\title{
Targeting ADG of Developing Replacement Heifers Using Age and Body Weight ${ }^{1}$
}

John Arthington and Philipe Moriel ${ }^{2}$

\section{Target Audience and Purpose}

This EDIS publication was prepared to assist beef cattle producers and livestock agents in determining the target ADG and management system to develop replacement beef heifers in Florida.

\section{Age and Body Weight at Puberty}

Heifer development continues to be one of the largest expenses to cow-calf operations, primarily due to cost of feed. Replacement heifers should be bred to calve at 24 months of age in order to maximize lifetime productivity of breeding females. Therefore, heifers should conceive at 15 months of age and achieve puberty at 13-14 months of age because heifers are infertile on the pubertal estrous cycle. For heifers to achieve puberty at 13-14 months of age, adequate nutrition is required to provide moderate rates of gain post-weaning $(1.5-2.0 \mathrm{lb} / \mathrm{d})$ so that heifers can achieve a critical body weight prior to reaching puberty. The average daily gain (ADG) needed to reach the target body weight depends upon body weight at weaning and number of days until the start of the breeding season.

Body weight is a primary determinant of puberty attainment in beef heifers. Beef heifers usually achieve puberty at $55 \%-60 \%$ of mature body weight with heifers of more Bos indicus breeding being at the upper end of this range. For instance, a recent three-year study conducted at Ona demonstrated that Brangus crossbred heifers achieved puberty at $56 \%-60 \%$ of mature body weight (assuming an average mature herd body weight of 1,100 lb) (Moriel et al. 2017; Moriel et al. 2020). Bos indicus heifers will also be older at puberty than Bos taurus heifers, making it even more difficult for Bos indicus and Bos indicus crossbred heifers to become pregnant and calve at 24 months of age. When developing replacement heifers, a target body weight method has been used, where heifers are provided a level of nutrition that will allow them to reach $60 \%-65 \%$ of mature body weight prior to the breeding season.

Recently, a dataset was compiled of published research data to evaluate the relationships among age and body weight at puberty and rate of gain from weaning to breeding in replacement beef heifers. This dataset includes Bos taurus, Bos indicus, and Bos taurus $\times$ Bos indicus heifers. Unfortunately, there are not enough data points of each breed type to evaluate the individual breed types. The results described are based on analysis including all breed types that may reflect the expected outcome of Bos taurus $\times$ Bos indicus breed type.

As post-weaning rate of gain increases, age at puberty decreases (Figure 1), which is expected because heifers will achieve the target body weight at a younger age. In Figure 2 , as post-weaning rate of gain increases, body weight at puberty increases, which may be unexpected based on the target body weight concept. Based on the target body weight concept, there should be no relationship between

1. This document is AN305, one of a series of the Department of Animal Sciences, UF/IFAS Extension. Original publication date September 2014. Revised October 2021. Visit the EDIS website at https://edis.ifas.ufl.edu for the currently supported version of this publication.

2. John Arthington, professor and center director, UF/IFAS Range Cattle Research and Education Center; and Philipe Moriel, associate professor, Department of Animal Sciences; UF/IFAS Range Cattle Research and Education Center, Ona, FL 33865.

The Institute of Food and Agricultural Sciences (IFAS) is an Equal Opportunity Institution authorized to provide research, educational information and other services

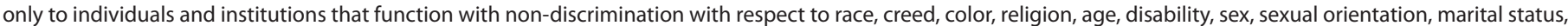

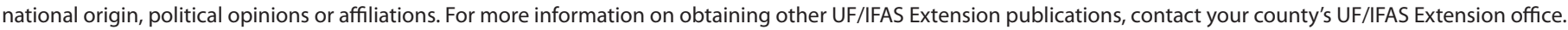
U.S. Department of Agriculture, UF/IFAS Extension Service, University of Florida, IFAS, Florida A \& M University Cooperative Extension Program, and Boards of County Commissioners Cooperating. Nick T. Place, dean for UF/IFAS Extension. 
body weight at puberty and post-weaning rate of gain. Once heifers reach $55 \%-60 \%$ of mature body weight, they should begin cycling no matter the rate of gain to get there. This indicates that other factors may be affecting attainment of puberty.

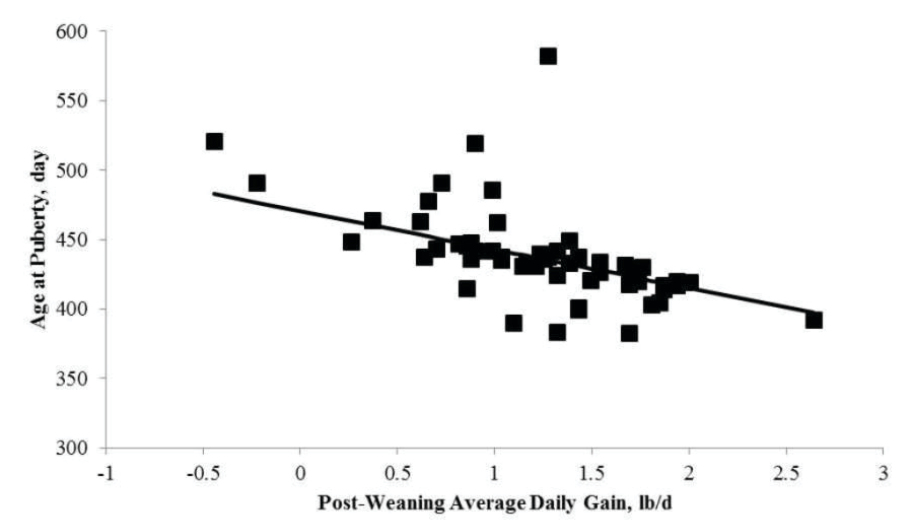

Figure 1. Relationship between age at puberty and post-weaning ADG in replacement beef heifers of Bos taurus, Bos indicus, and Bos taurus $\times$ Bos indicus breeding. Age $=470.55 \pm 22.31-27.72 \pm 5.62 \times A D G ; R^{2}=$ $0.34 ; P<0.01$.

Credits: John Arthington and Philipe Moriel

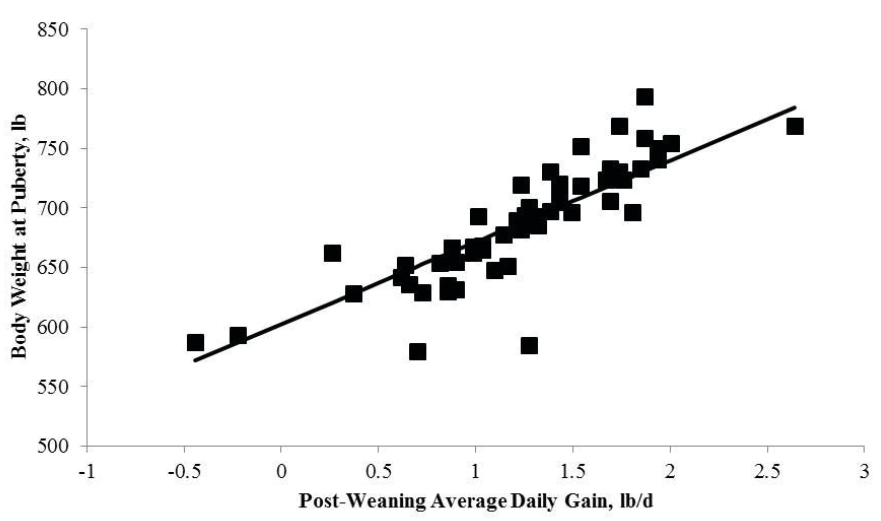

Figure 2. Relationship between body weight at puberty and postweaning ADG in replacement beef heifers of Bos taurus, Bos indicus, and Bos taurus $\times$ Bos indicus breeding. $B W=602.56 \pm 21.11+68.72 \pm$ $9.99 \times$ ADG; $\mathrm{R}^{2}=0.72 ; P<0.01$.

Credits: John Arthington and Philipe Moriel

One factor that may impact attainment of puberty in heifers is age. Previous research using five breeds and their crosses indicates that a minimum age and minimum body weight are required for heifers to achieve puberty (Nelsen et al. 1982). Thus, in the dataset compiled, it is possible that heifers fed for increased rates of gain surpassed the minimum body weight before the time they reached the minimum age necessary to attain puberty. This would result in these heifers having increased body weight at puberty. To evaluate whether a minimum age is required to achieve puberty, the relationship between age at puberty and body weight at puberty was determined (Figure 3). A definite break point is evident in this relationship such that even though body weight at puberty continues to increase, a minimum age at puberty is reached. This indicates that heifer development programs should utilize both a target body weight and minimum age. This would keep from overfeeding heifers to achieve target body weight before they have reached the minimum age that will allow them to achieve puberty, which may reduce feed costs of developing replacement heifers.

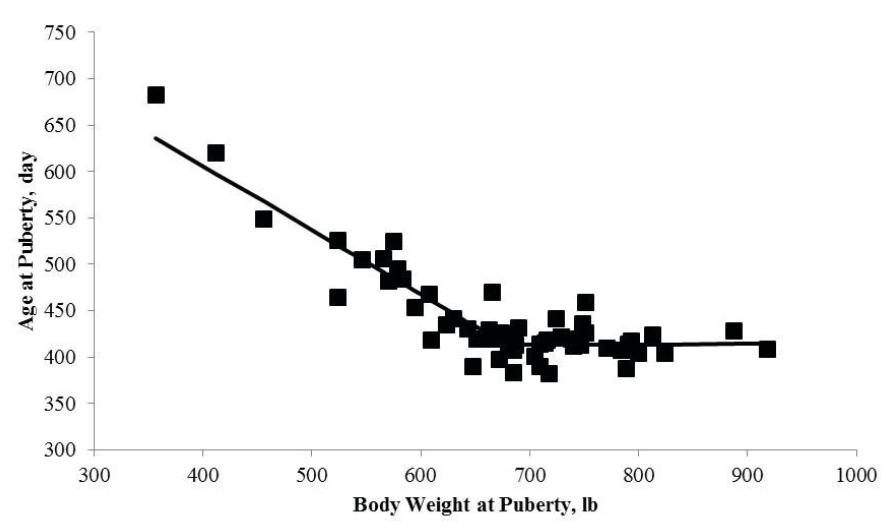

Figure 3. Relationship of age at puberty with body weight at puberty in replacement beef heifers of Bos taurus, Bos indicus, and Bos taurus $\times$ Bos indicus breeding. Age $=883.24 \pm 92.09-0.69 \pm 0.14 \times B W+0.70 \pm$ $0.19 \times B W$, where $B W \geq 679 \mathrm{lb} ; R^{2}=0.86 ; P<0.01$.

Credits: John Arthington and Philipe Moriel

It was determined from this analysis that the critical minimum age to achieve puberty was 412 days of age (13.7 months of age), which coincided with a body weight at puberty of $679 \mathrm{lb}$. This would represent $56.6 \%-61.7 \%$ of mature body weight, assuming mature body weight is between 1,100 and $1,200 \mathrm{lb}$, which is typical of cows found in Florida. Our three-year study demonstrated that Brangus crossbred heifers achieved puberty at 401-428 days of age and 610-654 lb of body weight (Moriel et al. 2017). Therefore, feeding heifers to reach $60 \%$ of mature body weight at 412 days of age would allow minimum age at puberty without overfeeding.

As a reminder, the analysis described here included Bos taurus, Bos indicus, and Bos taurus $\times$ Bos indicus heifers. The minimum age at puberty is most likely different for each breed type; caution should be taken when applying the specific minimum age at puberty described here to all breed types. The results of this analysis best reflect the minimum age for Bos taurus $\times$ Bos indicus heifers. Straight Bos taurus heifers are typically younger at puberty, whereas straight Bos indicus heifers are typically older at puberty.

\section{Pattern of Body Weight Gain}

The pattern of body weight gain prior to breeding can impact attainment of puberty by beef heifers. Heifer 
development programs can be designed for heifers to (1) have a constant rate of gain up to the start of breeding, (2) maintain weight early post-weaning and then gain weight rapidly just prior to breeding, or (3) gain weight rapidly early post-weaning and then maintain weight until the start of the breeding season. These three methods are illustrated in Figure 4.

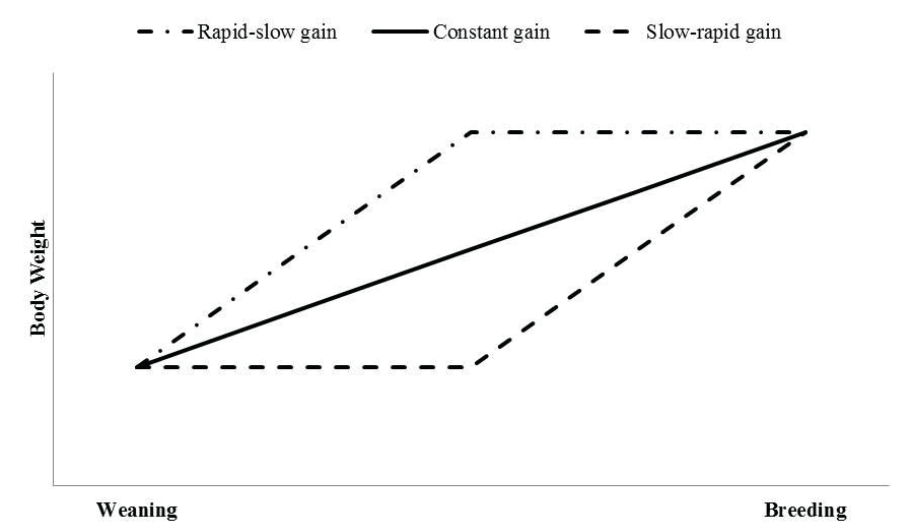

Figure 4. Illustration of different patterns of gain for replacement heifers from weaning to the start of the breeding season.

Credits: John Arthington and Philipe Moriel

The first method is to use a constant rate of gain from weaning to start of breeding. This method requires only moderate energy intake and supplemental feed. Using either of the other two methods (slow-rapid or rapid-slow) will require greater energy intake during the rapid gain period, but equal or less total supplemental feed over the entire feeding period, to attain similar body weight prior to breeding. This may not necessarily decrease feed costs, because feed costs associated with using slow-rapid gain versus constant gain will depend on the relative price of feed ingredients. The advantage of the slow-rapid gain method is that a lighter animal is maintained longer, which will reduce feed required for maintenance and potentially capitalize on compensatory gain of the heifer. However, if compensatory gain is not realized at the magnitude required to achieve a minimum body weight (due to severe drought and limited forage mass, for instance), heifers will not attain puberty before the start of the breeding season. Producers adopting the slow-rapid gain need to make sure that proper nutrition (backup hay and concentrate supplementation) will be available. Using the rapid-slow gain method may seem counterintuitive, because a heavier animal must be maintained late in the feeding period, which would increase feed required for maintenance. However, if less expensive, high-quality feedstuffs such as higher-quality forage are available early post-weaning, then this method may reduce heifer development costs.
Previous research evaluating patterns of body weight gain from weaning to breeding indicates that these methods can be successfully used to develop replacement heifers (Clanton et al. 1983; Hall et al. 1997; Lynch et al. 1997). However, an important aspect is the length of time heifers were fed a high-energy diet. In studies where heifers were fed for rapid gain for only 60 days, age at puberty and proportion of heifers cycling prior to breeding were reduced in the slow-rapid gain heifers even though body weight prior to breeding was similar to constant gain heifers. In contrast, studies where heifers were fed for rapid gain for 80-90 days either early post-weaning or immediately prior to the breeding season have reported similar age at puberty and pregnancy rates to constant gain heifers. Therefore, if slow-rapid or rapid-slow gain methods are used to develop replacement heifers, heifers should be fed a high-energy diet for a minimum of 80 days prior to reaching the target body weight, whether this is early post-weaning or immediately prior to the start of the breeding season.

\section{Early Weaning}

A couple of studies have demonstrated that early weaning and plane of nutrition for early-weaned heifers can significantly reduce age and body weight at puberty. In Angus and Simmental heifers, early weaning (112 days of age) and a high-energy diet decreased age at puberty by 100 days and body weight at puberty by 165 pounds compared with early weaning and a moderate-energy diet (Gasser et al. 2006). In a study at the UF/IFAS Range Cattle Research and Education Center, early weaning Brangus crossbred heifers (72 days of age) and feeding a high-energy diet until the time of normal weaning (249 days of age) decreased age at puberty by 131 days and body weight at puberty by 124 pounds compared with normal weaning (Moriel et al. 2014). Early weaning and feeding a high-energy diet also increased the proportion of heifers that were pubertal prior to the breeding season ( $100 \%$ vs. $30 \%$ for the early- and normal-weaned heifers, respectively). Additionally, early weaning and feeding the high-energy diet for only 94 days followed by grazing bahiagrass pastures gave similar results as feeding the high-energy diet for the entire 177 days.

Previous studies have reported that age at puberty or age at conception are negatively related with average daily gain pre-weaning, but not with average daily gain post-weaning. This indicates that heifers with faster growth rates preweaning attained puberty at a younger age. Additionally, a negative relationship between genetic potential for milk production and age at puberty has been reported, indicating that cows with greater milk yield produce heifers that achieve puberty at a younger age. Therefore, plane of 
nutrition early in life can significantly impact the ability of heifers to attain puberty prior to the breeding season. This response is attributed to the "metabolic imprinting" effect, a process in which nutrition at early stages of a calf's life is crucial for its development and future performance. For more information, see: EDIS publication AN335, Nutrition at Early Stages of Life Determines the Future Growth and Reproductive Performance of Beef Calves (Moriel 2021); and Nutrient Profiling-Metabolic Imprinting of Beef Calves (Moriel 2017).

Management practices to increase the plane of nutrition prior to normal weaning (e.g., early weaning and potentially creep feeding) could reduce age and body weight at puberty in beef heifers. However, the cost of extra feed (quality and quantity) and potential mortality losses associated with early weaning and creep feeding need to be considered when calculating the economic benefit of achieving puberty earlier or at a reduced body weight.

\section{Conclusion}

Developing beef heifers is a costly aspect of the cow-calf enterprise. Feeding heifers to reach the target body weight (60\% of mature weight) before reaching the minimum age that will allow them to attain puberty may increase feed costs. Using slow-rapid or rapid-slow gain methods could reduce feed costs, but a minimum of 80 days on a highenergy diet is recommended for heifers to attain puberty prior to the breeding season. Early-weaning heifers can dramatically decrease age and body weight at puberty and increase proportion of heifers cycling prior to the breeding season, but additional feed costs may be incurred using this development method.

\section{References}

Clanton, D. C., L. E. Jones, and M. E. England. 1983. "Effect of Rate and Time of Gain after Weaning on the Development of Replacement Beef Heifers." J. Anim. Sci. 56:280-285. https://doi.org/10.2527/jas1983.562280x

Gasser, C. L., D. E. Grum, M. L. Mussard, F. L. Fluharty, J. E. Kinder, and M. L. Day. 2006. "Induction of Precocious Puberty in Heifers I: Enhanced Secretion of Luteinizing Hormone." J. Anim. Sci. 84:2035-2041. https://doi. org/10.2527/jas.2005-636

Hall, J. B., R. B. Staigmiller, R. E. Short, R. A. Bellows, M. D. MacNeil, and S. E. Bellows. 1997. "Effect of Age and Pattern of Gain on Induction of Puberty with Progestin in Beef Heifers." J. Anim. Sci. 75:1606-1611. https://doi. org/10.2527/1997.7561606x
Lynch, J. M., G. C. Lamb, B. L. Miller, R. T. Brandt, Jr., R. C. Cochran, and J. E. Minton. 1997. "Influence of Timing of Gain on Growth and Reproductive Performance of Beef Replacement Heifers." J. Anim. Sci. 75:1715-1722. https:// doi.org/10.2527/1997.7571715x

Moriel, P., S. E. Johnson, J. M. B. Vendramini, V. R. G. Mercadante, M. J. Hersom, and J. D. Arthington. 2014. "Effects of Calf Weaning Age and Subsequent Management System on Growth and Reproductive Performance of Beef Heifers." J. Anim. Sci. 92:3096-3107. https://doi. org/10.2527/jas.2013-7389

Moriel, P. 2017. Nutrient Profiling-Metabolic Imprinting of Beef Calves. $6^{\text {th }}$ Annual Florida Beef Cattle Short Course, Gainesville, FL. http://animal.ifas.ufl.edu/beef_extension/ bcsc/2017/proceedings/moriel.pdf

Moriel, P., P. Lancaster, G. C. Lamb, J. M. B. Vendramini, and J. D. Arthington. 2017. "Effects of Post-Weaning Growth Rate and Puberty Induction Protocol on Reproductive Performance of Bos indicus-Influenced Beef Heifers." J. Anim. Sci. 95:3523-3531. https://doi.org/10.2527/ jas.2017.1666

Moriel, P., E. Palmer, M. Vedovatto, M. B. Piccolo, J. Ranches, H. M. Silva, V. R. G. Mercadante, G. C. Lamb, and J. M. B. Vendramini. 2020. "Supplementation Frequency and Amount Modulate Post-Weaning Growth and Reproductive Performance of Bos indicus-Influenced Beef Heifers." J. Anim. Sci. 98(8): 1-11. https://doi.org/10.1093/ jas/skaa236

Moriel, P. 2021. Nutrition at Early Stages of Life Determines the Future Growth and Reproductive Performance of Beef Calves. AN335. Gainesville: University of Florida Institute of Food and Agricultural Sciences. https://edis.ifas.ufl.edu/ an335

Nelsen, T. C., C. R. Long, and T. C. Cartwright. 1982. "Postinflection Growth in Straightbred and Crossbred Cattle. II. Relationships among Weight, Height, and Pubertal Characteristics." J. Anim. Sci. 55:293-304. https:// doi.org/10.2527/jas1982.552293x 